\title{
Continuous Electroencephalography Monitoring for Critically Ill Neonates: A Canadian Perspective
}

\author{
Sarah Grace Buttle (D), Erick Sell, Richard Webster, Melanie Varin, Brigitte Lemyre, \\ Cecil Hahn, Daniela Pohl
}

\begin{abstract}
Background: Continuous EEG monitoring, in the form of amplitude-integrated (aEEG) or conventional EEG (cEEG), is used in the neonatal intensive care unit (NICU) to detect subclinical central nervous system pathologies, inform management, and prognosticate neurodevelopmental outcomes. To learn more about provider attitudes and current practices in Canada, we evaluated neurologist and neonatologist opinions regarding NICU EEG monitoring. Methods: A 15-item electronic questionnaire was distributed to 114 pediatric neurologists and 176 neonatologists working across 25 sites. Results: The survey was completed by 87 of 290 physicians. Continuous EEG monitoring is utilized by $97 \%$ of pediatric neurologists and $92 \%$ of neonatologists. Neurologists and neonatologists differ in their EEG monitoring preferences. For seizure detection and diagnosis of encephalopathy, significantly more neonatologists favor aEEG alone or in combination with cEEG, whereas most neurologists prefer cEEG $(p=0.047,0.001)$. There is a significant difference in the perceived gaps in monitoring patients with cEEG between neonatologists (13\% would monitor more) and neurologists (41\% would monitor more) $(p=0.007)$. Half of all respondents $(53 \%)$ reported that they would be interested in attending an education session on neonatal EEG monitoring. Conclusions: Canadian neurologists and neonatologists do not agree on the best monitoring approach for critically ill neonates. Furthermore, neonatologists perceive a smaller cEEG monitoring gap as compared with neurologists. However, many participants from both specialties would like to increase long-term EEG monitoring in the NICU setting. Facilitating access to EEG monitoring and enhancing education may help to address these needs.
\end{abstract}

RÉSUMÉ: La surveillance continue par électroencéphalographie dans le cas de nouveau-nés gravement malades : une perspective canadienne. Contexte: La surveillance continue par électroencéphalographie (EEG), que ce soit à amplitude intégrée (EEGai) ou conventionnelle (EEGc), est utilisée dans les unités de soins intensifs néonatals (USIN) afin de détecter des pathologies sous-cliniques du système nerveux central, de fournir des indications en matière de prise en charge et d'établir des pronostics quant à l'évolution neuro-développementale de ces nouveau-nés. Afin d'en savoir plus au sujet des attitudes des prestataires de soins et des pratiques actuelles dans ce domaine au Canada, nous avons cherché à évaluer les points de vue de neurologues et de néonatologistes en ce qui regarde la surveillance continue par EEG dans les USIN. Méthodes: Un questionnaire en ligne abordant 15 aspects a été envoyé à 114 neuro-pédiatres et à 176 néonatologistes travaillant dans 25 établissements différents. Résultats: Ce sondage a été complété par 87 médecins sur 290. Il en ressort que la surveillance continue par EEG est utilisée par $97 \%$ des neuro-pédiatres et par $92 \%$ des néonatologistes. Cela dit, les neuropédiatres et les néonatologistes n'ont pas les mêmes préférences quant à l'utilisation de cet examen. Quand il s'agit de détecter des crises convulsives et de diagnostiquer des cas d'encéphalopathie, on remarque qu'un nombre nettement plus élevé de néonatologistes favorisent la seule EEGai ou la combinent avec la EEGc tandis que davantage de neurologues ont dit préférer la seule EEGc $(\mathrm{p}=0,047 ; \mathrm{p}=0,001)$. Qui plus est, on peut dénoter une différence notable entre les néonatologistes et les neurologues en ce qui a trait aux écarts perçus de surveillance des patients au moyen de la EEGc, $13 \%$ des premiers assurant une surveillance supérieure alors qu'ils sont $41 \%$ parmi les deuxièmes à assurer une surveillance supérieure $(p=0,007)$. Enfin, plus de la moitié des répondants $(53 \%)$ ont affirmé être intéressés à assister à des séances de formation portant sur la surveillance continue par EEG destinée aux nouveaunés. Conclusions: Les neurologues et les néonatologistes canadiens divergent quant à la meilleure approche de surveillance dans le cas de nouveau-nés gravement malades. En outre, les néonatologistes ont tendance à percevoir un écart de surveillance moins important si on les compare aux neurologues. Néanmoins, nombreux sont les répondants formés dans ces deux spécialités qui souhaiteraient augmenter à long terme la surveillance par EEG dans les USIN. Le fait de faciliter l'accès à ces examens et d'améliorer l'enseignement pourrait ainsi permettre de répondre aux besoins.

Keywords: EEG, Electroencephalography, Neonatal, Neurocritical care, Neonatal neurology

doi:10.1017/cjn.2019.36

Can J Neurol Sci. 2019; 46: 394-402

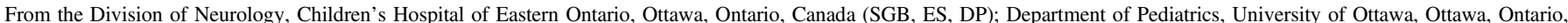

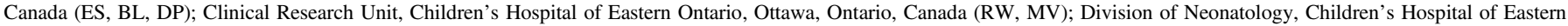

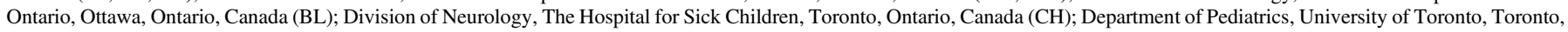
Ontario, Canada $(\mathrm{CH})$

Received August 7, 2018. Final Revisions Submitted February 18, 2019. Date of Acceptance March 16, 2019.

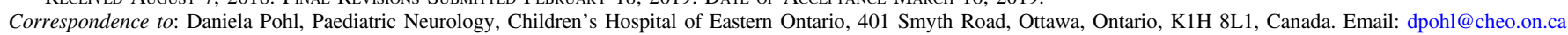




\section{INTRODUCTION}

Critically ill neonates are at a high risk of insults to their developing brains, which may result in neurodevelopmental deficits and even death if undetected and untreated. ${ }^{1}$ Seizures, particularly if untreated, may contribute to brain injury in the neonatal period. ${ }^{2}$ Electroencephalography (EEG) can detect seizures and subclinical central nervous system (CNS) pathologies, inform treatment decisions, and correlates with neurodevelopmental outcomes in neonates at risk of neurological impairment. ${ }^{1}$ Continuous EEG monitoring, in the form of amplitude-integrated EEG (aEEG) or conventional EEG (cEEG), is used in the neonatal intensive care unit (NICU) setting. Recently, aEEG has been reported to be the most widely used method of continuous CNS monitoring in NICUs. ${ }^{3}$ However, the sensitivity and specificity of aEEG are limited compared with cEEG. ${ }^{4,5}$ While cEEG is the gold standard for seizure detection, ${ }^{6}$ barriers to widespread implementation include the relatively high financial and personnel burdens associated with its use. ${ }^{7,8}$ Neonatal neurocritical care units have increasingly been established in Canada, ${ }^{9}$ further shaping the way EEG monitoring is being used during the neonatal period. However, despite the abundance of studies on the clinical utility of long-term EEG monitoring in the neonatal population, much is unknown regarding the attitudes of healthcare providers toward this tool in Canada. In our study, we conducted a nation-wide survey of NICU EEG monitoring practices and perceptions of Canadian pediatric neurologists and neonatologists.

\section{Methods}

\section{Survey Development}

A survey was developed with inputs from an interdisciplinary team, including a neonatologist (B.L.) and a pediatric neurologist (D.P.), at the Children's Hospital of Eastern Ontario (CHEO) in Ottawa, Canada. The survey was hosted via the CHEO REDCap instance. ${ }^{10} \mathrm{~A}$ pilot administration to all residents, fellows, and staff within the divisions of pediatric neurology and neonatology at $\mathrm{CHEO}$ was conducted. Feedback from the pilot administration was used to revise the final version of the survey, which was also reviewed by a pediatric neurologist (C.H.) with expertise in EEG monitoring at a separate Canadian center. A total of 15 items were included in the final version of the survey, including demographic information such as city and clinical area of practice, use and availability of long-term EEG monitoring in the NICU, and monitoring preferences in different clinical scenarios. For several survey questions the answers were a forced choice between categories. For example, for the question, "For how many patients in your NICU do you typically use each type of long term EEG monitoring in a 1-month period?" the options were: "0-1 patients per month," "2-8 patients per month," "9-14 patients per month," "15 or more patients per month," and "unable to provide an estimate." Forced-choice questions are quick to answer and have higher completion rates. The survey and study design (see Supplementary Material) were approved by both the Research Ethics Board (Project number 17/96X) and the Clinical Research Unit at CHEO.

\section{Recruitment and Data Collection}

The national survey administration occurred over a 1-month period in February 2018. Canadian neonatologists and pediatric neurologists with academic affiliations at hospitals with level-3
NICUs and whose contact information was publicly available were contacted to participate in the online survey via email. Efforts were made to confirm the accuracy of the final contact list through verification with individual faculties. Physicians who were retired from clinical service were excluded from the invitations, or from the final analysis, if such invitations were inadvertently sent. Individuals for whom the emails could not be successfully delivered were also excluded from the final sample size. Two reminders were sent prior to the survey closure. Consent was implied through completion of the survey.

\section{Data Analysis}

Survey data were collected and managed using REDCap. Statistical analyses were conducted in $\mathrm{R} .{ }^{11}$ Most of our analyses were performed at the individual physician level, where several individuals from the same hospital could contribute. This seemed a reasonable approach as there is variability in practice within hospitals according to preferences of individual physicians. The Fisher's exact test was chosen instead of the chi-squared test as it provides greater accuracy in scenarios with relatively small sample size. In cases where survey fields were left incomplete, efforts were made to include all available data, and sample sizes have been reported in such instances to indicate the number of responses per item.

Canada-wide EEG monitoring practices were examined via our institute-level analyses. There was a concern that there might be more respondents from larger hospitals, which could bias our findings. Therefore, to describe the Canada-wide EEG monitoring practices, we pooled data by institute to account for this overrepresentation of larger hospitals. In order for categorical variables to be pooled by institutes, the mode was calculated. The mode represents the most frequent answer per institute. For example, if an institute had three respondents who answered "less than daily," "daily," and "daily," the most frequent answer is daily (i.e., the mode). In cases where there are equal numbers of answers to one question, there would be several modes reported. For example, if an institute had two respondents who answered "less than daily" and "daily," all modes are reported. This allows our questions - that were designed to be categorical - to remain categorical in our pooled institute data.

Finally, comparing neonatologists and neurologists based on our data (where several institutes did not have responses from one specialty) may introduce bias. If an institute contributes information from only one specialty, there is uncertainty if reported attitudes/practices are due to institute, rather than specialty, differences. To minimize this possible bias, sub-analyses were performed including only institutes where both specialties responded.

\section{Results}

\section{Sample Characteristics}

The nationwide survey was completed by 87 of 290 physicians, representing 21 of 25 sites sampled. Response rates were similar for pediatric neurologists, 39 of 114 (34\%), and neonatologists, 48 of $176(27 \%)$. Out of the 87 physicians who completed the survey, five responded that they did not use EEG monitoring in their NICU and were excluded from further analyses. The final sample size was 82 physicians representing 21 institutions. For the purposes of statistical analysis, one individual who self-identified as an epileptologist was considered within the pediatric neurology group, and one individual who 


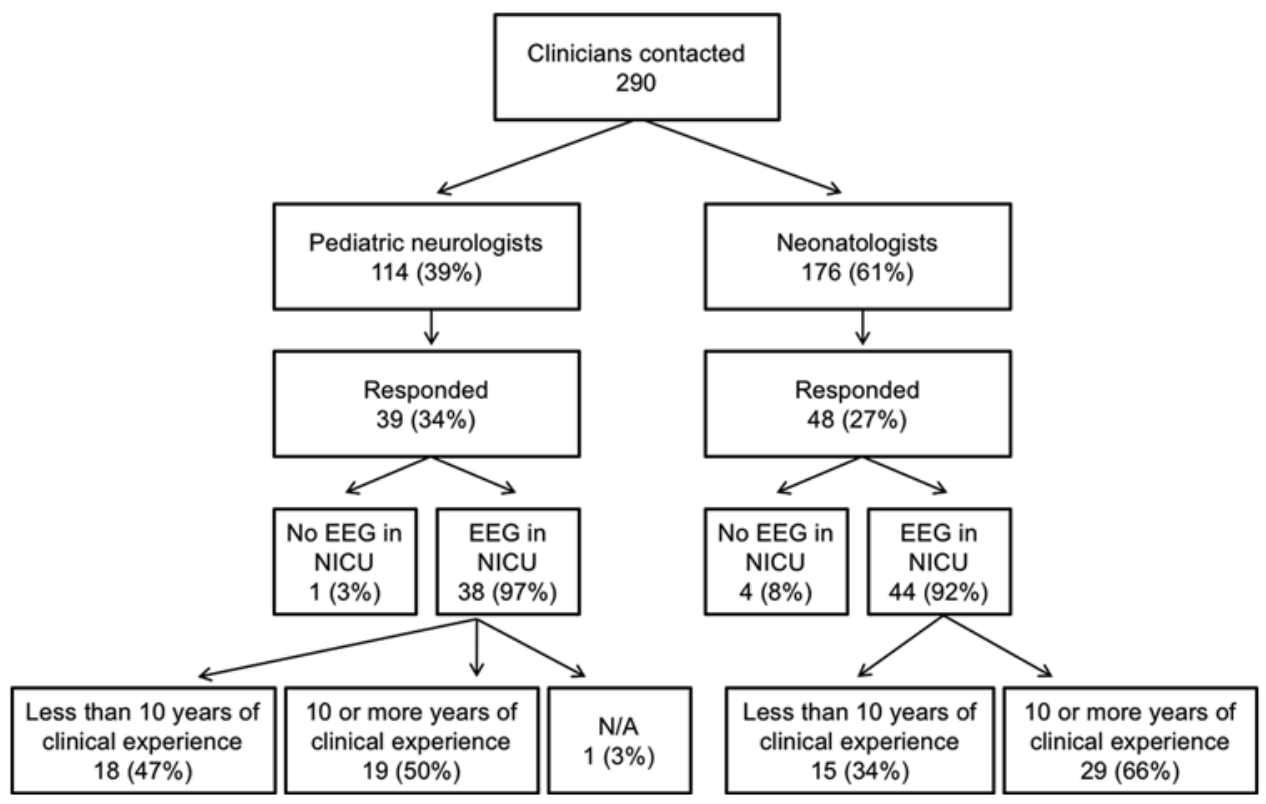

Figure 1: Flow diagram showing the response rate for each clinical specialty, whether EEGs are used in the respondent's NICU, and cohort breakdown by the level of clinical experience.

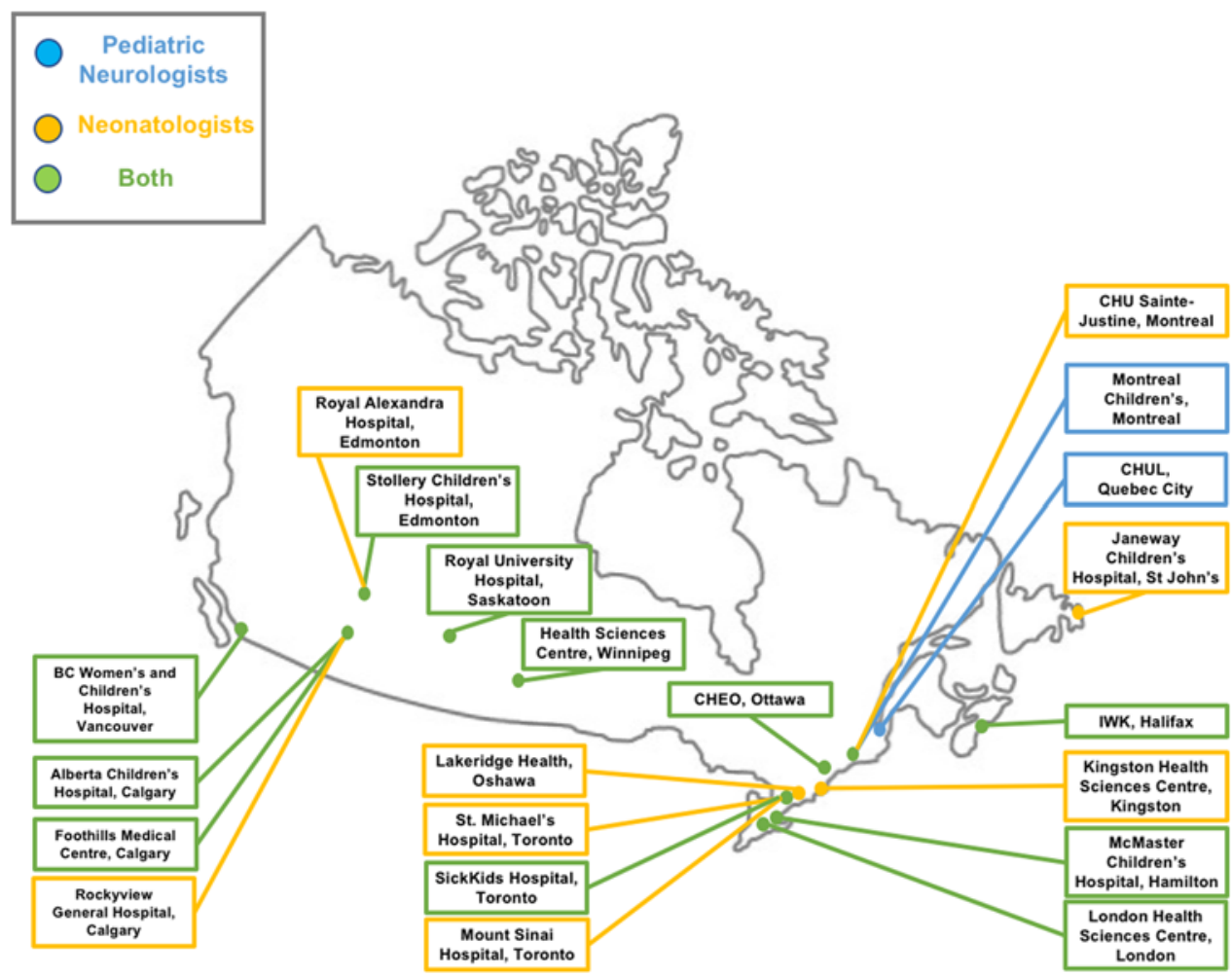

Figure 2: Geographic distribution of survey respondents.

self-identified as a general pediatrician was considered within the neonatology group. Figure 1 demonstrates participant characteristics with incomplete responses removed. Respondents were representative of 21 individual Canadian centers caring for critically ill neonates (Figure 2). Physicians who replied with the name of a university or city and not a hospital (e.g., "Toronto") were not included in this list of institutions. Access to EEG monitoring modalities at the individual level, by specialty, and method is depicted in Table 1.

Current Canada-wide EEG monitoring practices derived from the pooled data are presented in Table 2. Most centers reported monitoring between two and eight patients per month across all EEG modalities (cEEG, aEEG, and combined). Only two centers reported monitoring $\geq 15$ patients per month. 
Table 1: EEG usage by specialty, individual level

\begin{tabular}{c|c|c|c}
\hline EEG modality & $\begin{array}{c}\text { Neonatology } \\
(\boldsymbol{N}=\mathbf{4 4}), \boldsymbol{n}(\boldsymbol{\%})\end{array}$ & $\begin{array}{c}\text { Pediatric } \\
\text { neurology } \\
(\boldsymbol{N}=\mathbf{3 8}), \boldsymbol{n}(\boldsymbol{\%})\end{array}$ & $\boldsymbol{p}$-value \\
\hline $\begin{array}{c}\text { Only amplitude- } \\
\text { integrated EEG }\end{array}$ & $15(34)$ & $2(5)$ & 0.002 \\
\hline Conventional EEG & $29(66)$ & $36(95)$ & 0.002 \\
\hline $\begin{array}{c}\text { Conventional EEG } \\
\text { with video* }\end{array}$ & $27(61)^{* *}$ & $35(92)^{* *}$ & 0.002 \\
\hline $\begin{array}{c}\text { Combined cEEG } \\
\text { and aEEG }\end{array}$ & $21(48)$ & $25(66)$ & 0.121 \\
\hline
\end{tabular}

*cEEG with video use is defined at either sometimes or always.

**Sample size reduced to 40 for neonatology and 36 for pediatric neurology, as some participants did not answer this question.

Table 2: Institutional EEG monitoring practices by modality across Canada

\begin{tabular}{l|c|c|c}
\hline $\begin{array}{l}\text { Neonates } \\
\text { monitored per } \\
\text { month }\end{array}$ & cEEG, $\boldsymbol{n}$ (\%) & aEEG, $\boldsymbol{n}$ (\%) & $\begin{array}{l}\text { Combined (cEEG } \\
\text { and aEEG), } \boldsymbol{n} \text { (\%) }\end{array}$ \\
\hline $0-1$ patients & $8(35)$ & $4(19)$ & $8(35)$ \\
\hline $2-8$ patients & $10(44)$ & $14(67)$ & $12(52)$ \\
\hline 9-14 patients & $3(13)$ & $1(5)$ & $1(4)$ \\
\hline$\geq 15$ patients & $2(9)$ & $2(10)$ & $2(9)$ \\
\hline
\end{tabular}

\section{EEG Monitoring Practices of Pediatric Neurologists and Neonatologists}

Continuous EEG monitoring was utilized by $94 \%$ of respondents (97\% of pediatric neurologists, $92 \%$ of neonatologists). The reported reasons why continuous EEG was not used were that it was not available/accessible $(n=3)$, or only recently became available in the NICU $(n=1)$. Only one individual reported that EEG was not used because it did not inform treatment decisions.

We inquired as to how often participants regularly ( $>50 \%$ of the time) use EEG monitoring for different clinical scenarios. The most common clinical scenario monitored by participants with continuous EEG was patients with suspected seizures $(n=79)$. Other common indications for monitoring included therapeutic hypothermia $(n=73)$, HIE without therapeutic hypothermia $(n=62)$, and patients with CNS infections $(n=43)$. Self-reported indications for monitoring included metabolic disease $(n=4)$, intracranial hemorrhage $(n=3)$, stroke $(n=2)$, skull fracture or trauma $(n=2)$, preterm infants with abnormal movements $(n=2)$, paralyzed patients $(n=1)$, and hydrocephalus $(n=1)$.

Neonatologists were significantly more likely to state that aEEG informed management (49\%) compared with neurologists $(19 \%)(p=0.005)$. More neurologists $(63 \%)$ than neonatologists (35\%) perceived cEEG as informing management decisions in most patients, but this trend was not statistically significant $(p=0.07)$. Equivalent numbers of neurologists $(52 \%)$ and neonatologists $(42 \%)$ stated that combined cEEG/aEEG monitoring would inform management decisions in the majority of monitored patients $(p=0.823)$.
The frequency of EEG review varied considerably between neurologists and neonatologists. For example, the majority (65\%) of neonatologists reported checking aEEG more than once daily, and most (68\%) neurologists review cEEG more than once daily. When asked to specify, responses ranged from reviewing the EEG every 2 hours to reviewing EEGs twice daily. However, no neurologists reported checking cEEG at least once per hour, while $19 \%$ of neonatologists reported reviewing aEEG at that frequency (Table 3).

\section{Availability and Accessibility of EEG Monitoring in NICUs}

Availability was defined as having the equipment and personnel present to monitor a neonate. Accessibility was defined as how soon EEG could be applied once the indication for monitoring is established. Over $80 \%$ of respondents reported that aEEG was always (24 hours a day, 7 days per week) available in their NICUs, while only $10 \%$ reported that cEEG was always available (Table 4). The reported availability of aEEG was similar between neurologists and neonatologists $(p=0.066)$. However, the reported availability of cEEG differed significantly: more neurologists $(58 \%)$ than neonatologists $(25 \%)$ reported that cEEG is available during extended work hours $(p=0.005$; Figure 3$)$. This difference was not statistically significant when only considering responses from neonatologists and neurologists from centers that had at least one response from each specialty $(p=0.27)$. With regard to accessibility, $67 \%$ of respondents indicated that aEEG was immediately (within 1 hour) accessible as opposed to cEEG, for which a delay of 1-4 hours was reported by most (53\%) respondents, with $17 \%$ indicating cEEG was not routinely accessible in their NICUs. Neurologists were less likely to report delays in accessibility over 4 hours compared with neonatologists (Table 4).

\section{Preferred Monitoring Modalities}

Participants were asked about their preferred EEG modality for continuous monitoring in various clinical scenarios in the NICU, including detection of seizures and encephalopathy. Neurologists were significantly more likely to prefer cEEG for seizure detection, while neonatologists were significantly more likely to prefer aEEG in combination with cEEG to detect seizures $(p=0.047$; Figure 4$)$. Neurologists reported a significantly greater preference for cEEG to detect encephalopathy compared with neonatologists, who more often preferred aEEG either alone or in combination with cEEG for detecting encephalopathy $(p=0.001$; Figure 5$)$. When asked why practitioners have a preference for type of EEG, responses included "greater sensitivity and/or accuracy of cEEG" $(n=12)$, "more detailed information provided by cEEG" $(n=5)$, "use of combined monitoring for all patients" $(n=4)$, "better availability of aEEG" $(n=3)$, "familiarity with the modality" $(n=2)$, "use of aEEG as a first screening step in monitoring neonates" $(n=2)$, "cEEG not available or not used for long-term monitoring at an institution" $(n=2)$, and "enhanced diagnostic clarity with cEEG" $(n=1)$.

\section{Satisfaction with Current Monitoring Practices}

Participants were asked about their current monitoring practices, as well as what their monitoring practices would be if they had access to unlimited resources. The difference between current and desired usage was conceptualized as a monitoring gap. The 


\section{Table 3: Frequency of result interpretation by EEG modality and specialty}

\begin{tabular}{|c|c|c|c|c|}
\hline EEG review frequency & $\begin{array}{l}\text { Neonatology cEEG } \\
\quad(N=41), n(\%)\end{array}$ & $\begin{array}{l}\text { Neurology cEEG } \\
(N=37), n(\%)\end{array}$ & $\begin{array}{l}\text { Neonatology aEEG } \\
\quad(N=43), n(\%)\end{array}$ & $\begin{array}{c}\text { Neurology aEEG } \\
(N=31), n(\%)\end{array}$ \\
\hline No routine review & $7(17)$ & $3(8)$ & $1(2)$ & $14(45)$ \\
\hline $\begin{array}{l}\text { Only when results are officially } \\
\text { reported }\end{array}$ & $21(51)$ & $0(0)$ & $1(2)$ & $1(3)$ \\
\hline Less than daily & $1(2)$ & $0(0)$ & $0(0)$ & $2(7)$ \\
\hline Daily & $3(7)$ & $9(24)$ & $5(12)$ & $4(13)$ \\
\hline More than once daily & $8(20)$ & $25(68)$ & $28(65)$ & $7(23)$ \\
\hline At least once per hour & $1(2)$ & $0(0)$ & $8(19)$ & $3(10)$ \\
\hline
\end{tabular}

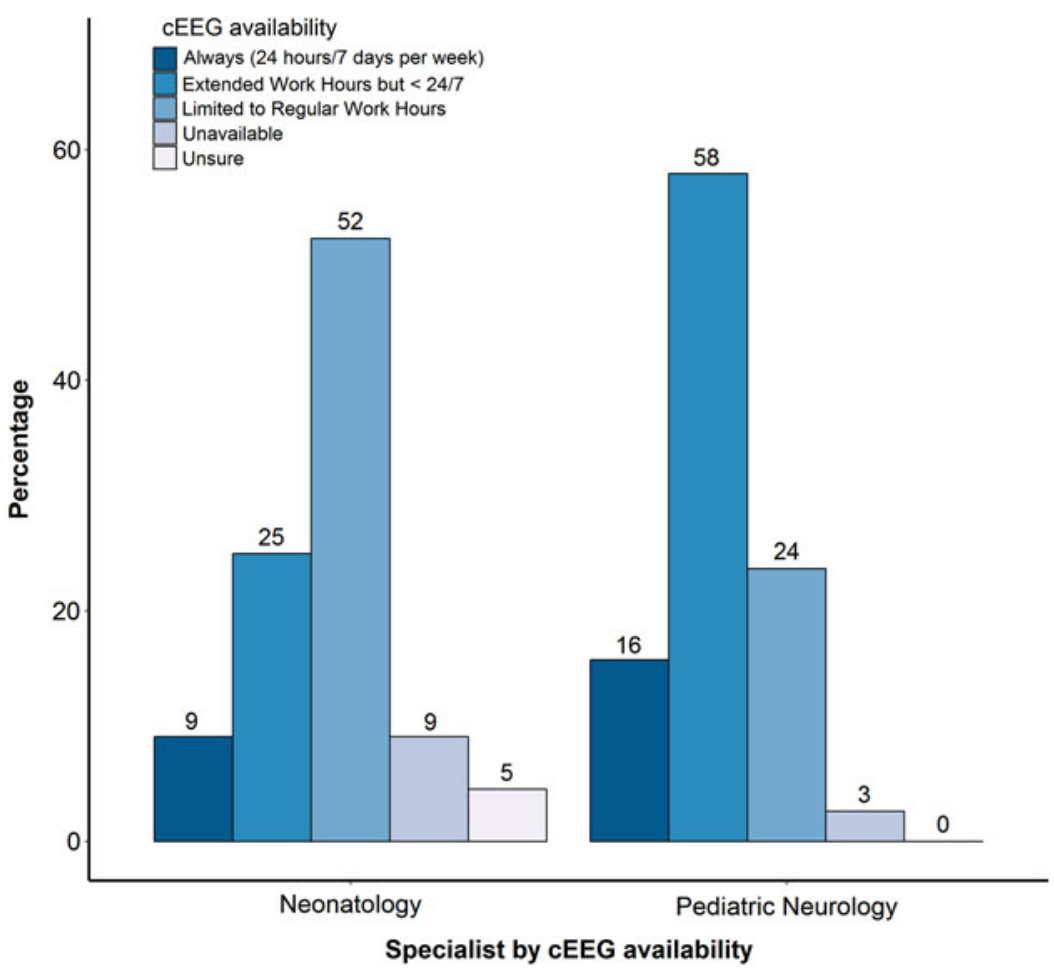

Figure 3: Perceived availability of cEEG for pediatric neurologists and neonatologists.

perceived gap in monitoring patients with cEEG was significantly higher in neurologists ( $41 \%$ would monitor more) than in neonatologists $(13 \%$ would monitor more) $(p=0.007)$. In contrast, there was an opposite trend for the perceived gap for aEEG monitoring: $12 \%$ of neurologists versus $20 \%$ of neonatologists would monitor more $(p=0.529)$ and the perceived gap for combined aEEG/cEEG monitoring was very similar between the subspecialties: $24 \%$ of neurologists and $20 \%$ of neonatologists would like to do more combined monitoring if they had unlimited resources $(p=0.780)$ (Figure 6).

\section{Interest in Further Education on EEG Monitoring in the NICU}

Approximately half of all respondents (53\%) reported that they would be interested in attending an education session on continuous EEG in the NICU. Pediatric neurologists and neonatologists were equally interested in further education in this area $(55 \%$ vs. $51 \%)$. Reasons why survey respondents were not interested in further education on this topic included having already completed training $(n=11)$, currently feeling competent $(n=1)$, or having limited NICU exposure in their practice $(n=1)$.

\section{Discussion}

This study is the first national assessment of EEG monitoring in Canadian NICUs. Our results capture the monitoring practices and perceptions of approximately one-third of the Canadian neurologists and neonatologists caring for critically ill infants, representing 21 separate institutions. Uniformly, Canadian practitioners caring for critically ill neonates recognize the role of EEG monitoring in managing patients with neurological concerns, and almost all view it as a favorable tool.

Our results indicate that $94 \%$ of respondents use some form of EEG monitoring for their NICU patients, a slight increase over an international (North America and Europe) utilization rate 


\section{Table 4: Perceived availability and accessibility of EEG monitoring in NICUs by modality (pooled institutional and specialty data)}

\begin{tabular}{l|c|c}
\hline & cEEG, $\boldsymbol{n}(\%)$ & aEEG, $\boldsymbol{n}(\%)$ \\
\hline $\begin{array}{c}\text { Always (24 hours/7 days } \\
\text { per week) }\end{array}$ & $3(10)$ & $21(81)$ \\
\hline $\begin{array}{l}\text { Extended work hours but } \\
<24 / 7\end{array}$ & $10(33)$ & $2(8)$ \\
\hline $\begin{array}{l}\text { Limited to regular work } \\
\text { hours }\end{array}$ & $13(43)$ & $1(4)$ \\
\hline Unavailable & $3(10)$ & $0(0)$ \\
\hline Unsure & $1(3)$ & $2(8)$ \\
\hline & Accessibility of EEG & $18(67)$ \\
\hline $\begin{array}{l}\text { Immediately (within 1 } \\
\text { hour) }\end{array}$ & $1(3)$ & $4(15)$ \\
\hline Within 1-4 hours & $16(53)$ & $0(0)$ \\
\hline Within 5-8 hours & $3(10)$ & $0(0)$ \\
\hline Within 9-24 hours & $4(13)$ & $1(4)$ \\
\hline Not routinely accessible & $5(17)$ & $4(15)$ \\
\hline I don't know & $1(3)$ &
\end{tabular}

reported almost 10 years ago of $90 \% .^{12}$ It is unclear whether this is the result of improved access to EEG technology in general, or whether Canadian utilization is truly higher than the international average. While our results indicate that most neurologists (97\%) and neonatologists (91\%) incorporate EEG monitoring into their practices, practitioners from the two specialties often differ in which EEG modality they prefer: for most clinical scenarios, the majority of neurologists prefer cEEG, while neonatologists prefer aEEG. These results are similar to previous surveys of EEG use in the NICU ${ }^{12}$ and consistent with our local institutional observations that each subspecialty tends to prefer their own monitoring modality, possibly due to familiarity, accessibility, timeliness of EEG analysis, or perceived confidence in interpretation.

Canadian neurologists report a shorter delay in the application of cEEG than neonatologists in our survey (Table 3). The fact that cEEG was perceived as more accessible to neurologists than neonatologists may be due to the close relationship that neurologists have with neurophysiology services and technicians. ${ }^{13}$ Alternatively, neurologists may perceive less of a delay in the application of cEEG monitoring because they are consulted by neonatology, who are more often the first physicians to establish an indication for monitoring and thus experience greater delays from the time a requirement for monitoring is identified until the patient is connected to continuous monitoring. Overall, the discrepancies in the availability and accessibility of long-term EEG monitoring between specialties highlight the need for effective collaboration between subspecialties to improve patient care.

Our results indicate that there is considerable variability in the availability of cEEG monitoring across Canada. Most centers had cEEG monitoring available during either regular or extended work hours; three centers had 24/7 access, and three centers had no cEEG access at all (Table 4). While our initial analysis suggested that neurologists reported greater availability in cEEG monitoring in the NICU compared with neonatologists $(p=0.005)$, our sub-analysis shows there is no significant difference in the availability of cEEG between specialties $(p=0.27)$. This conflicting result could be due to either (1) successfully removing the institute sampling bias or (2) the reduction in sample size that diminishes the statistical power. Additionally, our results demonstrate that even when continuous EEG is available, in most instances the tracings are not continuously reviewed. Many respondents reported reviewing EEG more than once per day, but the actual frequency of checks varied from every 2 hours to twice per day. Only $19 \%$ of neonatologists reported reviewing aEEG at least once per hour, and no neurologists reported reviewing cEEG that frequently. Moreover, half (51\%) of neonatologists indicated that they only check cEEG results when the final report is produced, which may occur days after the monitoring period has concluded. This practice is concerning as even if EEG monitoring is present, our results indicate the EEGs are not being reviewed often, creating the potential for a delay in the recognition of seizures or other abnormal findings.

Of note, 15 Canadian centers reported the use of combined aEEG/cEEG monitoring in their NICUs (Table 2), which combines the convenience of bedside aEEG monitoring with the higher sensitivity and specificity of cEEG. This approach may facilitate co-management by neonatology and neurology and may allow for more rapid detection of abnormalities, leading to improved management of critically ill neonates. ${ }^{13}$ Further research into the clinical and economic benefits of this approach is needed to determine whether such practices produce enhanced outcomes for patients.

One novel aspect of our survey was to capture perceptions regarding monitoring gaps, that is, the number of patients a physician would wish to monitor if they had unlimited resources, compared with the number they are currently monitoring. In Canada, significantly more pediatric neurologists $(41 \%)$ than neonatologists $(13 \%)$ reported a desire to monitor more patients with cEEG. Our results suggest that neurologists perceive a greater utility of cEEG than do neonatologists. This is possibly because neonatologists are satisfied with current practices of aEEG monitoring and may not be aware of the limitations of aEEG and the additional diagnostic clarification that cEEG can provide. Approximately half (53\%) of neurologists and neonatologists in our survey indicated they would be interested in attending an education session on neonatal EEG, suggesting that many respondents would be open to learning more about recent advances in this field. There is a growing body of literature demonstrating that cEEG is much more sensitive and specific than aEEG in detecting seizures and other abnormalities of brain function ${ }^{5-8}$ Further, a recent diagnostic accuracy study of aEEG in detecting seizures in neonates concluded that aEEG is suboptimal for seizure detection and making treatment decisions. ${ }^{14}$ Therefore, continuing education sessions on this subject may increase uptake of cEEG by neonatologists and neurologists.

There are several potential limitations to our study. While approximately one in three clinicians caring for critically ill neonates in Canada responded to the survey, generalizability may be limited by negative response bias (nonresponse error). The relatively low response rate may be secondary to the survey modality used. Prior work has demonstrated average response rates of $38 \%$ when surveying physicians using internet-based tools, compared with an average of $57 \%$ using paper-based 


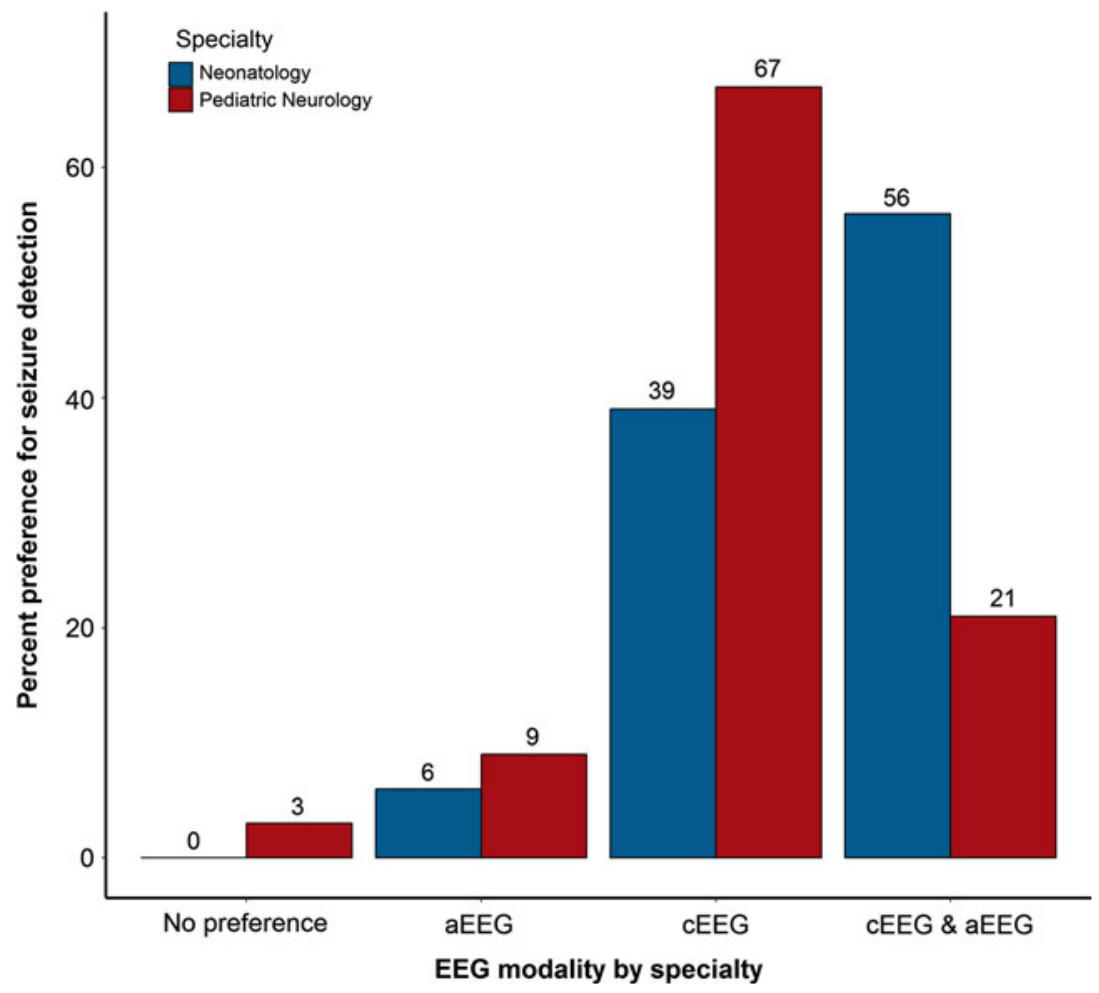

Figure 4: Preferred EEG monitoring modality for seizure detection, by specialty.

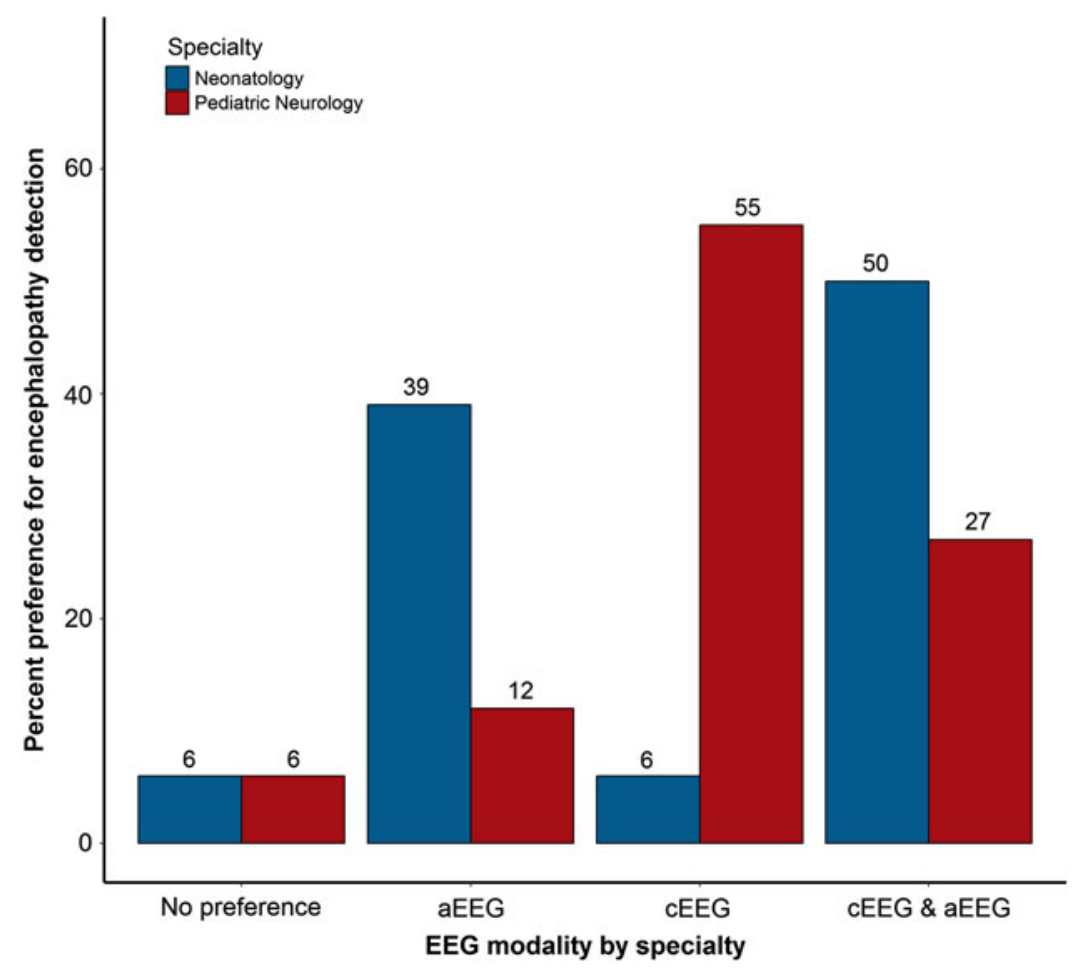

Figure 5: Preferred EEG monitoring modality for encephalopathy detection, by specialty. 


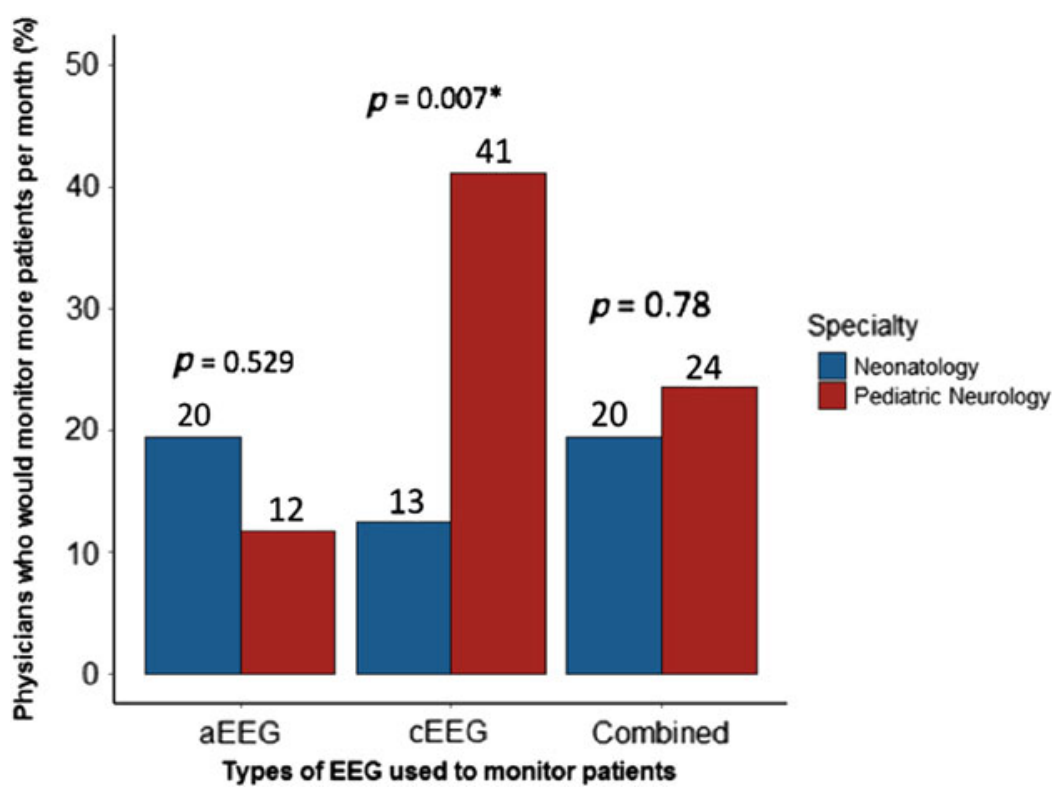

Figure 6: Percentages of physicians who would like to monitor more than current practice, by specialty and EEG modality. See Table 1 in Supplementary Materials for supporting data.

methods. ${ }^{15}$ The method of participant recruitment (convenience sampling) may also be partially responsible for the lower response rate obtained in our study: we were restricted to using only contact information for practitioners that was publicly available, for example, on hospital and university websites. Efforts were made to contact department administrators to confirm the accuracy of contact information available. However, we are assuming that we did not have the correct or most up-to-date information for some physicians, who would then not have completed our questionnaire, thereby decreasing the overall response rate. Still, it is somewhat disappointing that not more practitioners answered this survey, as EEG monitoring in NICU settings is a common practice shared between both neurologists and neonatologists. While overall our survey produced a lower response rate than we had hoped, our survey respondents still represented a breadth of geographic coverage across Canada, contributing to the generalizability of our findings at a national scale.

In many cases, several responses were received per institution. To accommodate for any interrater differences between responses from the same center, we calculated institutional modes. Additional limitations of our survey include self-reporting bias and the convenience sampling method employed. While the current recruitment strategy may have limited opportunities for community practitioners to respond, these physicians are less likely to encounter continuous EEG monitoring in the NICU setting given the nature of their practice. Relative under-coverage of Quebec may limit generalizability outside of English Canada, given the lack of publicly available contact information for practitioners in that province. At the survey design phase, we did not consider asking about seizure detection algorithms. By excluding this information, the frequency at which the staff read EEGs might provide an underestimation of how EEGs are being monitored.

\section{Conclusions}

Our study demonstrates that there is considerable inter-center variability in neonatal EEG monitoring across Canada. Due to inconsistent availability and accessibility, not all Canadian neonates are monitored equally. Many practitioners report a monitoring gap, suggesting that increased EEG monitoring is desired. Of note, neurologists and neonatologists do not agree on the best monitoring approach for critically ill neonates, indicating an opportunity for improved communication, collaboration, and education of both specialties. The information obtained from this survey may inform policies regarding access to neonatal EEG monitoring across Canada, with the ultimate aim of achieving better outcomes for this vulnerable patient group.

\section{ACKNOWLEDGements}

Thank you to the participating neurologists and neonatologists across Canada. This project was completed as part of the Faculty of Medicine Undergraduate Leadership Certificate Program at the University of Ottawa.

\section{Disclosures}

None of the authors have any disclosures or conflicts of interest to report.

\section{Statement of Authorship}

SGB and DP conceptualized the project. SGB, DP, ES, CH, and BL contributed to survey design and data collection. MV and RW completed data analysis and interpretation. SGB and DP drafted the article, and all authors critically edited and reviewed it. DP supervised this work. All authors have approved the final version of this article.

\section{SUPPLEMENTARY Material}

To view supplementary material for this article, please visit http://dx.doi.org/10.1017/cjn.2019.36. 


\section{REFERENCES}

1. Chalak LF, Tarumi T, Zhang R. The 'neurovascular unit approach' to evaluate mechanisms of dysfunctional autoregulation in asphyxiated newborns in the era of hypothermia therapy. Early Hum Dev. 2014;90(10):687-94.

2. Johnston MV, Fatemi A, Wilson MA, Northington F. Treatment advances in neonatal neuroprotection and neurointensive care. Lancet Neurol. 2011;10:372-82.

3. Boylan G, Stevenson NJ, Vanhatalo S. Monitoring neonatal seizures. Semin Fetal Neonatal Med. 2013;18(4):202-8.

4. Rakshasbhuvankar A, Paul S, Nagarajan L, Ghosh S, Rao S. Amplitude-integrated EEG for detection of neonatal seizures: a systematic review. Seizure. 2015;33:90-8.

5. Buttle SG, Lemyre B, Sell E, et al. Combined conventional and amplitude integrated EEG monitoring in neonates: a prospective study. J Child Neurol. 2019. doi: 10.1177/0883073819829256.

6. Shellhaas RA, Chang T, Tsuchida T, et al. The American clinical neurophysiology society's guideline on continuous electroencephalography monitoring in neonates. J Clin Neurophysiol. 2011;28(6):611-7.

7. Cherian PJ, Deburchgraeve W, Swarte RM, et al. Validation of a new automated neonatal seizure detection system: a clinician's perspective. Clin Neurophysiol. 2011;122(8):1490-9.

8. Wietstock SO, Bonifacio SL, Sullivan JE, Nash KB, Glass HC. Continuous video electroencephalographic (EEG) monitoring for electrographic seizure diagnosis in neonates. J Child Neurol. 2016;31(3):328-32.
9. Bashir RA, Espinoza L, Vayalthrikkovil S, et al. Implementation of a neurocritical care program: improved seizure detection and decreased antiseizure medication at discharge in neonates with hypoxic-ischemic encephalopathy. Pediatr Neurol. 2016; 64:38-43.

10. Harris PA, Taylor R, Thielke R, Payne J, Gonzalez N, Conde JG. Research electronic data capture (REDCap)-A metadata-driven methodology and workflow process for providing translational research informatics support. J Biomed Inform. 2009;42(2): 377-81.

11. R core team. R: a language and environment for statistical computing. R Found Stat Comput. Vienna, Austria: R Foundation for Statistical Computing; 2017.

12. Boylan G, Burgoyne L, Moore C, O'Flaherty B, Rennie J. An international survey of EEG use in the neonatal intensive care unit. Acta Paediatr. 2010;99(8):1150-5.

13. Glass HC, Rogers EE, Peloquin S, Bonifacio SL. Interdisciplinary approach to neurocritical care in the intensive care nursery. Semin Pediatr Neurol. 2014;21(4):241-7.

14. Rakshasbhuvankar A, Rao S, Palumbo L, Ghosh S, Nagarajan L. Amplitude integrated electroencephalography compared with conventional video EEG for neonatal seizure detection: a diagnostic accuracy study. J Child Neurol. 2017;32(9): 815-22.

15. Cho YI, Johnson TP, VanGeest JB. Enhancing surveys of health care professionals: a meta-analysis of techniques to improve response. Eval Heal Prof. 2013;36(3):382-407. 